\title{
Patterns of financial incentives in primary healthcare settings in Nigeria: implications for the productivity of frontline health workers
}

\author{
Ekechi Okereke* (10, George Eluwa, Akinwumi Akinola, Ibrahim Suleiman, Godwin Unumeri and Sylvia Adebajo
}

\begin{abstract}
Objective: This study was designed to explore the patterns of financial incentives received by some frontline health workers (including nurses, midwives as well as community health workers in paid employment) and the implications for their productivity within rural settings in Nigeria. A cross-sectional quantitative design in two States in Nigeria was adopted. Structured interviews were conducted with 114 frontline health workers. Bivariate analysis and multivariate regression analysis were carried out to explore relationships between the satisfaction of frontline health workers with the financial incentives received and their productivity in rural settings as well as the extent of any such relationships.

Results: Bivariate analysis demonstrated a statistically significant relationship $(P=0.013)$ between satisfaction with incentives received by frontline health workers and their productivity in rural settings. When other predictors were controlled for within a multivariate regression model, those who received incentives and were satisfied with the incentives were about three times more likely to be more productive at work than those who were unsatisfied with incentives (AOR: 3.3; $\mathrm{P}=0.009,95 \% \mathrm{Cl}=1.3-8.2$ ). In conclusion, the determination of type and content of incentives should be done in consultation with all relevant stakeholders, including possibly a cross-section of health workers themselves.
\end{abstract}

Keywords: Incentives, Frontline health workers, Productivity, Primary healthcare, Nigeria

\section{Introduction}

A properly motivated health workforce is a prerequisite for effective maternal, newborn and child health $(\mathrm{MNCH})$ service delivery $[1,2,3]$. Globally, there are challenges associated with improving the productivity and retention of frontline health workers especially in rural communities [4]. The factors that influence the productivity of frontline health workers within primary healthcare settings in low- and middle-income countries need to be further researched and documented.

Nigeria, the most populous country in sub-Saharan Africa has poor maternal, newborn and child morbidity

*Correspondence: eokereke78@gmail.com; eokereke@popcouncil.org Population Council, 16 Mafemi Crescent, off Solomon Lar Way, Utako, Abuja, Nigeria and mortality indices $[5,6]$. The country's infant and under-five mortality rates from the 2018 National Demographic and Health Survey (NDHS) indicate that infant and under- 5 mortality rates are 67 and 132 deaths per 1000 live births respectively [7]. The Nigerian health system is divided into the tertiary, secondary and primary healthcare systems, depending on which level of government is responsible for management, the type of healthcare services provided as well as healthcare personnel available to provide healthcare services. The tertiary healthcare system is managed and resourced by the Federal Government, the secondary health system is managed and resourced by the respective State governments, while the primary health system is managed by the Local governments. Although nurses and midwives are available at all levels of the healthcare system 
in Nigeria, community health workers i.e., community health officers (CHOs), community health extension workers (CHEWs) and Junior community health workers (JCHEWs) are only available and provide healthcare services at the primary healthcare level [8].

According to National Guidelines for the development of primary healthcare systems in Nigeria, JCHEWs are expected to provide essential community-based services such as promoting the community's participation in health-related activities, conducting home visits and clients' follow up as well as identifying and registering pregnant women for antenatal care. The JCHEWs should spend about $90 \%$ of their time working within the community but in addition they provide some basic healthcare services within assigned health facilities, especially in rural communities. The CHEWs have similar community-based functions as the JCHEWs but tend to spend less time (about $40 \%$ or less of their time) working in the community and more time working within health facilities, promoting maternal and child healthcare and managing patients according to basic clinical protocols. The community health officer tends to have more administrative roles within the health facility, but with similar community-based functions and facility-based maternal newborn and child healthcare $(\mathrm{MNCH})$ responsibilities as the CHEWs [9].

The primary health care system in Nigeria is inadequately financed and poorly functioning with dire consequences for frontline health workers' productivity at primary healthcare level [10]. One of the key strategies for increasing frontline health workforce availability and productivity within rural communities is through the introduction and use of incentives [11, 12, 13]. This is more so, when remunerations for health workers are poor and insufficient to cover the most basic needs of health workers and their families [14, 15]. Increasing salaries is not a 'magic bullet' for dealing with the problem of poor availability and productivity of frontline health workers, because better salaries do not necessarily translate to increased productivity and retention among health workers [3].

The human resources for health $(\mathrm{HRH})$ project in Nigeria was implemented by Population Council and the World Health Organization (WHO). The HRH project carried out a study in some rural communities within Bauchi and Cross River states to assess the implications of financial incentives on the productivity of specific frontline health workers as well as to investigate the relationship between satisfaction with the financial incentives received by these frontline health workers and their productivity in rural primary healthcare settings in Nigeria. Frontline health workers as defined within the $\mathrm{HRH}$ project and applied to this research study refer to nurses, midwives and community health workers i.e. CHEWs, JCHEWs and CHOs.

\section{Main text \\ Methods \\ Study sites}

This study was conducted in Alkaleri and Giade local government areas (LGAs) in Bauchi State in NorthEast Nigeria as well as Etung and Yala LGAs in Cross River State, within the southern part of the country. The study was undertaken in Bauchi and Cross-river states because these were the HRH project focal states in Nigeria.

\section{Study design and sampling procedure}

The study employed a cross-sectional quantitative research design. To conduct the sampling for the study, the list of LGAs in Bauchi and Cross River states were stratified into urban and rural. This was followed by a random selection of two rural LGAs per State-Alkaleri and Giade LGAs in Bauchi state; Yala and Etung LGAs in Cross River state using the compiled list of rural LGAs for each state as the sampling frame. A list of PHC facilities which offered maternal, newborn and child health services was stratified as Health posts, Primary Health Clinics and Primary Healthcare Centres from which an equal representation of these different types of facilities were selected.

One hundred and fourteen (114) frontline health workers i.e. community health extension workers (CHEW), junior community health extension workers (JCHEW), community health officers (CHOs), nurses and midwives were selected from sixty-six (66) randomly selected primary healthcare facilities in Bauchi and Cross River states. These 66 health facilities represent half of all available primary healthcare facilities in the randomly selected rural LGAs within the study states, based on a sampling approach used by Adeniyi and colleagues [16].

\section{Data collection and management}

Data collection was undertaken by monitoring and evaluation (M\&E) officers from selected Local Government Areas (LGAs) in each state, who were trained on the use of the study questionnaire (see sample as Additional file 2) as well as on research ethics. The study questionnaires were first pilot-tested, then the pre-tested questionnaires were uploaded on personal digital assistants (PDAs) and used to collect self-reported data from the survey respondents. Data analysis was done using SPSS software. 


\section{Definition and measurement of productivity of FLHWs for this study}

Financial incentives for this study were defined as additional monetary payments that contribute to health workforce productivity. The World Health Organization has identified productivity as one of the outcomes to measure health workforce performance [17]. Jaskiewicz $\mathrm{W}$ and her colleague defined productivity as healthcare services provided by a healthcare worker over a given period of time [18]. However, productivity for this study is defined as the number of patients/clients to which a frontline health worker provides healthcare services on a daily basis for a full time equivalent (FTE) of $40 \mathrm{~h} /$ week. Consequently, productivity for this study was measured using two proxies: (1) average number of patients/clients seen daily by a frontline health worker (client load) and (2) number of hours of work per week by a frontline health worker (level of effort). Calculations using data collected from the health facilities involved in the study estimated ' 7 patients per day' as the average number of patients attended by frontline health workers per day. Thus, a frontline health worker who attended to over 7 patients per day was categorized as having 'adequate' client load while those who attended to 7 patients and below on average per day were categorized as having inadequate client load. Furthermore, the minimum weekly hours of work/level of effort required for frontline health workers was estimated at $40 \mathrm{~h} /$ week, hence frontline health workers who spent $40 \mathrm{~h}$ or more at their work were categorized as having 'adequate' level of effort while those who spent below $40 \mathrm{~h} /$ week were categorized as having 'inadequate' level of effort. Frontline health workers with adequate client load and simultaneously having adequate level of effort were categorized as frontline health workers with adequate productivity, others were classified as frontline health workers with inadequate productivity.

\section{Ethical considerations}

Ethical approval was granted by Bauchi and Cross River States' Research Ethical Committees and Population Council's Institutional Review Board (IRB). Written informed consent was sought and obtained from each study respondent prior to starting the interviews for the study.

\section{Results \\ Key characteristics of frontline health workers}

A total of 114 frontline health workers from Bauchi (43\%) and Cross River state (57\%) were enrolled into this study. The majority (over 85\%) were 30 years and above and married (91\%) while more than half (59\%) were females.
CHEWs constituted the largest (47\%) proportion of respondents, followed by JCHEWs (45\%) while nurses (1\%) and midwives (2\%) were few working at primary healthcare level in both states.

\section{Incentives received by frontline health workers at primary health care facilities}

Over half (51.8\%) of the frontline health workers received some form of financial incentive, but majority (61.4\%) were unsatisfied with the incentives which they received (Table 1). The types of financial incentives received ranged from rural posting allowance (66\%); stipends for adhoc jobs such as immunization (20\%); loans (20\%); per diem for conference attendance $(35 \%)$ or trainings (40\%). About a quarter $(27 \%)$ and $3 \%$ reported receiving reimbursements for transport fare and money for referrals respectively as financial incentives. Beyond their primary occupation as health care providers, most frontline health workers engaged in farming $(70 \%)$ or petty trading (16\%). A few operated as patent medicine vendors (6\%) and home birth attendants (9\%) to augment their incomes (see Additional file 1: Tables S1 and S2).

\section{Bivariate analysis}

Bivariate analysis was carried out to explore relationships between frontline health workers' satisfaction with incentives and their productivity within rural primary healthcare settings. There was a statistically significant relationship $(\mathrm{P}=0.013)$ between frontline health workers' satisfaction with incentives and their productivity in rural primary healthcare settings. Adequate productivity was higher (46\% vs. $23 \%$ ) among frontline health workers who reported being satisfied with the incentives compared to those who reported not being satisfied with incentives (Table 2).

\section{Multivariate analysis}

To ascertain the extent of the relationship between satisfaction with incentives and frontline health workforce productivity, binomial regression was conducted as shown in Table 3. Results from unadjusted regression reveals that health workers who were satisfied with incentives were 2.8 times more likely to demonstrate better productivity at their work than those who were unsatisfied with the incentives $(\mathrm{P}=0.013, \mathrm{CI}=1.3-6.3)$. When other predictors were controlled for, those who were satisfied with incentives were 3.3 times more likely to be more productive at their work than those who are unsatisfied with incentives $(\mathrm{P}=0.009, \mathrm{CI}=1.3-8.2)$.

\section{Discussion}

This study was designed to explore the financial incentives received by some frontline health workers (nurses, 
Table 1 Key characteristics of frontline health workers enrolled into the study $(\mathrm{N}=114)$

\begin{tabular}{|c|c|c|}
\hline Characteristic & $\mathrm{N}$ & $\%$ \\
\hline \multicolumn{3}{|l|}{ State } \\
\hline Bauchi & 49 & 43.0 \\
\hline Cross River & 65 & 57.0 \\
\hline \multicolumn{3}{|l|}{ Sex } \\
\hline Male & 47 & 41.2 \\
\hline Female & 67 & 58.8 \\
\hline \multicolumn{3}{|l|}{ Age } \\
\hline$\leq 29 \mathrm{yrs}$ & 15 & 13.2 \\
\hline $30-39$ yrs & 51 & 44.7 \\
\hline 40 yrs above & 48 & 42.1 \\
\hline \multicolumn{3}{|l|}{ Marital status } \\
\hline Married & 104 & 91.2 \\
\hline Single/widowed & 10 & 8.8 \\
\hline \multicolumn{3}{|l|}{ Religion } \\
\hline Christianity & 76 & 66.7 \\
\hline Islam & 38 & 33.3 \\
\hline \multicolumn{3}{|l|}{ Education } \\
\hline Post-secondary school & 112 & 98.2 \\
\hline University degree and above & 2 & 1.8 \\
\hline \multicolumn{3}{|l|}{ Type of FLHW } \\
\hline JCHEW & 51 & 44.7 \\
\hline CHEW & 53 & 46.5 \\
\hline $\mathrm{CHO}$ & 7 & 6.1 \\
\hline Nurse & 1 & 0.9 \\
\hline Midwife & 2 & 1.8 \\
\hline \multicolumn{3}{|l|}{ Years in PHC } \\
\hline$<2$ years & 30 & 26.3 \\
\hline $2-4$ years & 45 & 39.5 \\
\hline 5 yrs and above & 39 & 34.2 \\
\hline \multicolumn{3}{|l|}{ Years in current position } \\
\hline$<2$ yrs & 34 & 29.8 \\
\hline $2-4$ yrs & 49 & 43.0 \\
\hline 5 yrs and above & 31 & 27.2 \\
\hline \multicolumn{3}{|l|}{ Received financial incentive } \\
\hline Yes & 59 & 51.8 \\
\hline No & 55 & 48.2 \\
\hline \multicolumn{3}{|l|}{ Satisfaction with incentives } \\
\hline Satisfied & 44 & 38.6 \\
\hline Unsatisfied & 70 & 61.4 \\
\hline
\end{tabular}

midwives and community health workers) which could influence their availability and productivity with possible consequences for primary healthcare service delivery in Nigeria. Community health workers constitute over $95 \%$ of the sample of frontline health workers who were involved in this study. Current financial incentives within primary healthcare settings in Nigeria may
Table 2 Bivariate analysis between satisfaction with incentives received for $\mathrm{MNCH}$ work and health workforce productivity at PHC level

\begin{tabular}{lllll}
\hline Characteristic & $\begin{array}{l}\text { Inadequate } \\
\text { productivity } \\
\text { (\%) }\end{array}$ & $\begin{array}{l}\text { Adequate } \\
\text { productivity } \\
\text { (\%) }\end{array}$ & $\mathbf{X}^{2}$ & P value \\
\hline Level of satisfaction with incentives for MNCH work & & \\
Satisfied & 54.5 & 45.5 & 6.385 & 0.013 \\
Unsatisfied & 77.1 & 22.9 & & \\
\hline
\end{tabular}

be more applicable to these cadres of frontline health workers. Nurses and midwives were scarce within the primary healthcare facilities involved in this study and this is largely reflective of the current dearth of nurses and midwives in most health facilities within rural communities and in primary healthcare settings across Nigeria. This finding raises concerns about the geographical imbalances of frontline health workers and its impact on delivering universal healthcare [19]. It is likely that the majority of the current financial incentives available at this level of care-primary healthcare, may not be sufficient enough to adequately retain nurses and midwives. In addition, nurses and midwives appear to have better opportunities to migrate to higher levels of the healthcare delivery system, where more lucrative financial and non-financial incentive mechanisms exist.

Slightly over half $(52 \%)$ of the frontline health workers enrolled in this study received some form of financial incentive while working in rural and primary healthcare settings. Around two-thirds of frontline health workers involved in this study received rural posting allowance. However, it is imperative to give rural posting allowance to every frontline health worker working in rural communities to incentivize them to take up the responsibility to provide healthcare services and remain working within rural and primary healthcare settings [4]. Rural posting allowance for frontline health workers should be attractive enough to encourage/persuade health workers to ignore the opportunities which are available in urban settings and encourage their retention in rural areas. State and Federal governments should possibly introduce policies which encourage private sector organizations to apply their corporate social responsibilities towards initiatives which motivate frontline health workers for example by introducing different types of incentives. Various stakeholders including donors such as the World Bank, should collaborate with governments at different levels to introduce, implement and sustain incentives [10] to improve the productivity of frontline health workers in rural and primary healthcare settings. 
Table 3 Predictors of frontline health workers' productivity at primary healthcare level

\begin{tabular}{lll}
\hline Characteristic & Univariate analysis OR (95\% Cl) & $\begin{array}{l}\text { Multivariate } \\
\text { analysis OR } \\
\mathbf{( 9 5 \%} \mathbf{C l})\end{array}$ \\
\hline Facility type & & 0181 \\
Health clinic & 0.193 & Ref. \\
Health post & Ref. & $0.5(0.1-2.0)$ \\
PHC & $0.4(0.1-1.5)$ & $1.5(0.5-4.6)$ \\
Sex & $1.1(0.4-3.1)$ & 0.067 \\
Female & 0.091 & Ref. \\
Male & Ref. & $2.3(0.9-5.7)$ \\
Age & $1.9(0.9-4.5)$ & 0.957 \\
$>4$ yrs & 0.735 & Ref. \\
30-3 yrs & Ref. & $1.2(0.3-4.5)$ \\
<2 yrs & $1.1(0.5-2.6)$ & $1.0(0.4-2.7)$ \\
Education & $1.6(0.5-5.4)$ & 0.959 \\
Post-sec school & 0.581 & Ref. \\
University degree and above & Ref. & $0.9(0.1-18.3)$ \\
Satisfaction with incentive for MNCH work & $2.2(0.1-36.1)$ & 0.009 \\
Unsatisfactory incentive & $<0.013$ & Ref. \\
Satisfactory incentive & Ref. & $3.3(1.3-8.23)$ \\
\hline
\end{tabular}

Possible consequences when the salaries and income of frontline health workers are not enough could include scenarios where health workers seek alternative sources of income, sometimes to the detriment of healthcare services provided to patients and clients [1]. The study findings indicate that about $70 \%$ of respondents engage in farming as an alternative source of income-this is not unusual considering that majority of these frontline health workers reside in rural communities with a lot of agricultural land. About $16 \%$ of the study respondents indicated involvement in some form of petty trading, with some health workers providing patent medicine $(6 \%)$ and home birth attendance services (9\%). These findings which illustrate that frontline health workers get involved in other economic activities to supplement their income is consistent with what has been reported elsewhere-Akwataghibe and colleagues reported that out of 165 respondents, over half of health workers indicated having additional medical or non-medical earning arrangements, the majority (over 40\%) reported involvement in nonmedical activities such as farming and trading [14].

Bivariate analysis suggests that satisfaction of frontline health workers with financial incentives has a relationship with their productivity. In other words, if frontline health workers perceive/regard the incentives which they receive as satisfactory, then this will very likely improve their productivity. Multivariate regression analysis indicated that those who received incentives and were satisfied with the incentives were about three times likely to be more productive at their work than those who were unsatisfied with incentives. These findings strengthen the argument for the need to introduce, implement and sustain context-appropriate incentives which frontline health workers regard as satisfactory to encourage their retention in rural communities as well as improve their productivity. However, to develop interventions which promote a high productivity workforce, requires a proper understanding of the current $\mathrm{HRH}$ situation and effective management and planning practices [20].

It is important that there are necessary consultations with all the relevant stakeholders about the type and content of incentives [21], including possibly with a crosssection of health workers or the professional associations of health workers who receive the incentives. A comprehensive strategy for improving frontline health workforce productivity should ideally include a mixture of financial and non-financial incentives [10] as well as consider the human resources for health situation within rural and primary healthcare settings, particularly for low- and middle-income countries [21].

\section{Limitations}

The study has some limitations such as the possibility of response bias among study respondents. In addition, the study has a relatively small sample size from across the different cadres of frontline health workers at primary healthcare level-nurses, midwives, community health officers, community health extension workers and junior community health extension workers. 


\section{Abbreviations}

CHEW: Community health extension worker; $\mathrm{CHO}$ : Community health officer; FLHW: Frontline health worker; GAC: Global Affairs Canada; HRH: Human resources for health; IRB: Institutional review board; JCHEW: Junior community health extension worker; LGA: Local government area; MNCH: Maternal newborn and child health; NDHS: National demographic and health survey; PDA: Personal digital assistant; PHC: Primary health care; SPSS: Statistical package for social sciences; WHO: World Health Organization.

\section{Supplementary Information}

The online version contains supplementary material available at https://doi. org/10.1186/s13104-021-05671-z.

Additional file 1: Table S1. Major sources and types of financial incentives for frontline health workers $(N=59)$. Table S2. Other economic activities of frontline health workers $(\mathrm{N}=114)$.

Additional file 2. Frontline Health Worker Questionnaire.

\section{Acknowledgements}

The authors express heartfelt thanks to the donor of the HRH project-GAC, however the views expressed within the manuscript are those of the authors and not the views of GAC. The authors also wish to acknowledge the support provided by the Bauchi and Cross-River States' Ministries of Health and State Primary Healthcare Development Agencies, as well as the collaboration with $\mathrm{WHO}$ in Nigeria during the implementation of the $\mathrm{HRH}$ project.

\section{Authors' contributions}

EO conceptualized the study. EO developed the initial draft of the paper along with IS and GU. Data analysis was carried out by EO, GE and AA. GE, AA and SA provided critical feedback for the finalization of the paper. EO serves as the corresponding author for the paper. All authors read and approved the final manuscript.

\section{Authors' information}

All the authors of this paper are staff of Population Council in Nigeria. The lead author (Ekechi Okereke) works as the HRH Project Director for Population Council in Nigeria.

\section{Funding}

This research was carried out as part of the Human Resources for Health $(\mathrm{HRH})$ project, implemented in Nigeria by Population Council and the World Health Organization with funding provided by the Canadian Government via Global Affairs Canada (GAC).

\section{Availability of data and materials}

The datasets for this study are available from the corresponding author upon reasonable request.

\section{Declarations}

\section{Ethics approval and consent to participate}

Ethical approval was obtained from the Research Ethical Committees of Bauchi and Cross River States in Nigeria as well as Population Council's Institutional Review Board (IRB) in the USA. Written informed consent was sought and obtained from each study respondent prior to starting the interviews for the study.

\section{Consent for publication}

Appropriate consent forms (in accordance with Population Council's consent procedures) were utilized for the study, including consent for publication.

\section{Competing interests}

The authors declare that they have no competing interests.

\section{References}

1. Dieleman M, Cuong PV, Anh LV, Martineau T. Identifying factors for job motivation of rural health workers in North Viet Nam. Hum Resour Health. 2003;1(1):10.

2. Franco LM, Bennett S, Kanfer R. Health sector reform and publicsector health worker motivation: a conceptual framework. Soc Sci Med. 2002:54:1255-66

3. Mathauer I, Imhoff I. Health worker motivation in Africa: the role of nonfinancial incentives and human resource management tools. Hum Resour Health. 2006;4:24.

4. Prytherch $\mathrm{H}$, Kagone M, Aninanya GA, Williams JE, Kakoko DCV, Leshabari MT, Ye M, Marx M, Sauerborn R. Motivation and incentives of rural maternal neonatal health care providers: a comparison of qualitative findings from Burkina Faso, Ghana and Tanzania. BMC Health Serv Res. 2013;13:149.

5. Rowe AK, Savigny D, Lanata CF, Victoria CG. How can we achieve and maintain high-quality performance of health workers in low-resource settings? Lancet. 2005;366:1026-35.

6. Kana MA, Doctor HV, Peleteiro B, Lunet N, Barros H. Maternal and child health interventions in Nigeria: a systematic review of published studies from 1990 to 2014. BMC Public Health. 2015;15:334.

7. National Population Commission (NPC) [Nigeria] and ICF 2019. Nigeria demographic and health survey 2018. Abuja, Nigeria and Rockville, Maryland, USA: NPC and ICF.

8. Okpani Al, Abimbola S. Operationalizing universal health coverage in Nigeria through social health insurance. Niger Med J. 2015;56(5):305-10.

9. National Primary Healthcare Development Agency. National guidelines for development of primary healthcare system in Nigeria. 4th ed. Abuja: National Primary Healthcare Development Agency; 2012.

10. Bhatnagar A, George AS. Motivating health workers up to a limit: partial effects of performance-based financing on working environments in Nigeria. Health Policy Plan. 2016:31(7):868-77.

11. Fox S, Witter S, Mafuta E, Lievens T. Paying health workers for performance in a fragmented, fragile state: reflections from Katanga Province, Democratic Republic of Congo. Health Policy Plan. 2013;29:96-105.

12. Marko V, Weber SE, Nikolic IA, Rifat A, Ranjana K. An analysis of GAVI, the global fund and world bank support for human resources for health in developing countries. Health Policy Plan. 2012;27:649-57.

13. Magrath P, Nichter M. Paying for performance and the social relations of health care provision: an anthropological perspective. Soc Sci Med. 2012;75:1778-85.

14. Akwataghibe N, Samaranayake D, Lemiere C, Dieleman M. Assessing health workers' revenues and coping strategies in Nigeria — a mixed methods study. BMC Health Serv Res. 2013;13:387.

15. Ferrinho $P, O \operatorname{mar} M$, Fernandes M. Pilfering for survival: how health workers use access to drugs as a coping strategy. Hum Resour Health. 2004;2:4.

16. Adeniyi J, Oladepo O, Soyibo A. Study of primary health care delivery service in Nigeria: a quantitative survey approach. Washington DC: World Bank; 2004.

17. World Health Organization. The world health report 2006. Geneva: Working Together for Health; 2006.

18. Jaskiewicz W, Tulenko K. Increasing community health worker productivity and effectiveness: a review of the influence of the work environment. Hum Resour Health. 2012:10:38.

19. Macaia D, Lapão LV. The current situation of human resources for health in the province of Cabinda in Angola: is it a limitation to provide universal access to healthcare? Hum Resour Health. 2017;15(1):88.

20. WHO. Health workforce requirements for universal health coverage and the sustainable development goals. Human Resources for Health Observer, Issue No. 17. 2016; Geneva: WHO.

21. Eboreime EA, Abimbola S, Obi FA, et al. Evaluating the sub-national fidelity of national initiatives in decentralized health systems: integrated primary healthcare governance in Nigeria. BMC Health Serv Res. 2017;17:227.

\section{Publisher's Note}

Springer Nature remains neutral with regard to jurisdictional claims in published maps and institutional affiliations.

Received: 12 February 2021 Accepted: 23 June 2021

Published online: 30 June 2021 